\title{
Attempts at the Creation of a Prosthetic Venous Valve in the Treatment of Chronic Venous Disease
}

\author{
Yolanda Bryce*, Sharath Kumar and Paul Booth \\ Memorial Sloan Kettering Cancer Center, USA
}

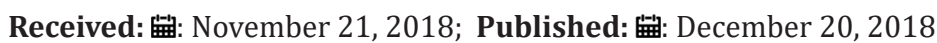

*Corresponding author: Yolanda Bryce, Memorial Sloan Kettering Cancer Center, New York, USA

\section{Mini Review}

Chronic Venous Disease (CVD) affects more than 25 million people with $20 \%$ of patients developing the most severe form of disease of large gaping nonhealing leg wounds with skin break down and exudative ulceration (Figure 1) [1,2]. CVD is caused by irreversible damage to the venous valves (one-way valves that promote the one-way flow of blood from the legs to the heart and inhibit blood from pooling at the ankles and causing venous hypertension) leading to varicose veins, leg pain, swelling and leg ulcers and wounds [2]. Risk factors include prior Deep Venous Thrombosis (DVT), hereditary disorder, prolonged standing/ sitting, and obesity [2]. The prognosis of venous ulcers is poor with delayed healing and recurrence. Annually, an estimated $\$ 3$ billion are spent in the treatment of chronic venous wounds [3]. Surgical and percutaneous solutions have been undertaken to recreate the damaged venous valves without success [4]. There are no commercially available artificial venous valves due to high failure rates and biocompatibility issues.

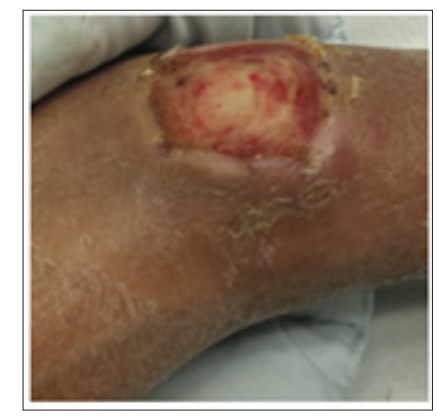

Figure 1: Patient with history of DVT resulting in severe chronic venous disease and large nonhealing venous ulcer.

In 2013, Philips M et al. [5] reported taking a segment of internal jugular veins of 16 sheep, enclosing them circumferentially with a barbed stent and surgically transferring them to a contralateral internal jugular vein [5]. In a similar fashion, a segment of axillary vein was transferred to the popliteal vein in 4 human males, average age 22, with recalcitrant ulcers, and followed for 3.8 years [5]. The results were promising with 6-month patency in the sheep and improvement in the venous ulcers in the human males [5]. This study created a record that prosthetic venous valves, at least, transposed venous valves, is a tangible endeavor. A dedicated group led by Dusan Pavcnik performed committed work, with multiple noted publications, to answer the need for prosthetic venous valves to aid this large population of patients suffering from life-altering venous ulcers. They used both autologous venous valves and freeze-dried small intestinal submucosa attached to metal stents and implanted them percutaneously into a vein $[6,7]$. The results were initially promising however, the subject would undertake an exuberant process of foreign body reaction, resulting in thickening and incompetence of the venous valve [6,7]. Similarly, Gomez-Jorge et al. [8] took a segment of glutaraldehyde-fixed bovine external jugular vein with valves and sutured them to a nitinol stent and implanted them into the IVC or right external iliac veins of 11 swine [8]. At 2 weeks, histopathology of the stents demonstrated inflammatory granulomatous response and foreign-body reaction [8]. The persistent inflammatory stimulus of the foreign body material lead to foreign body reaction and resulted in thickening and incompetence of the valve due $[9,10]$. As is, the thin construct of a native venous valve (Figure $2 \mathrm{~A} \& 2 \mathrm{~B}$ ) is ultimately not emulated by these previous attempts at creating a venous valve.

To combat the issues of persistent inflammatory stimulus and foreign body response, some have turned to tissue engineering to create a protective endothelial layer, a process called endothelialization, given the anti-inflammatory properties of a healthy endothelial layer. One group, for example, has used 
decellularized jugular ovine vein conduits containing valves and reseeding them with cultured peripheral blood endothelial cells at variable flow conditions [11]. They discovered that with their method, endothelial cells could be successfully cultured and reestablished on the luminal surface of a decellularized venous valve under different flow conditions [11]. Additionally, Weber et al. [12] used tri- and bicuspid venous valves based on polyglycolic acidpoly-4-hydroxybutyrate composite scaffolds, fully biodegradable scaffolds, integrated into self-expandable nitinol stents [12]. They then engineered autologous ovine bone-marrow-derived mesenchymal stem cells and endothelialized the biodegradable scaffolds [12]. Here, a combination of biodegradability and endothelialization was used to combat an inflammatory foreign body reaction [12]. These studies are preliminary and additional work is needed.
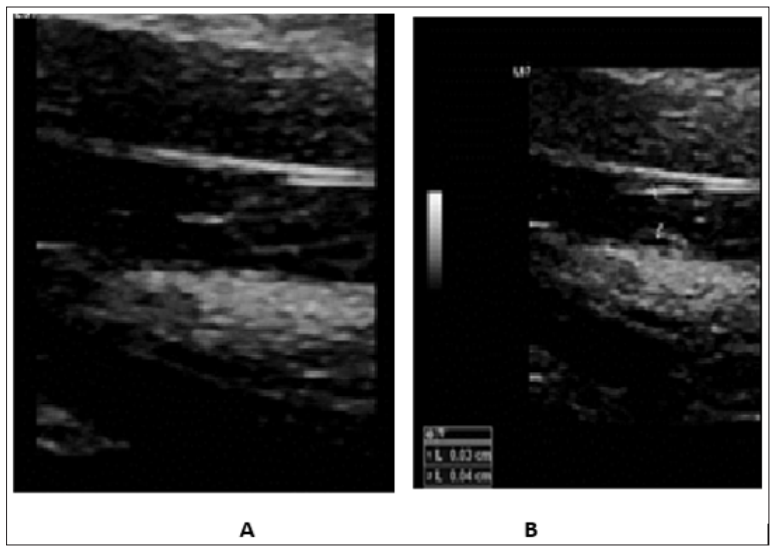

Figure 2: Demonstration of our evaluation of venous valves with ultrasound. A. Venous Valves closed. B. Venous valves opened which we use to measure thickness.

\section{Conclusion}

In conclusion, chronic venous disease is debilitating and is due to irreversibly damaged native venous valves. Multiple unsuccessful attempts at recreating the native venous valve have not as yet produced long term results, at least in part, due to an inflammatory foreign body response to the prosthetic venous valve. More studies are forthcoming to combat the issues surrounding these failures, in order to develop a viable solution for chronic venous disease.

\section{References}

1. Beebe Dimmer JL, Pfeifer JR, Engle JS, Schottenfeld D (2005) The epidemiology of chronic venous insufficiency and varicose veins. Ann Epidemiol 15(3): 175-184.

2. Eberhardt R, Raffetto J (2014) Chronic venous insufficiency. Circulation 130(4): 333-346.

3. Nherera L, Woodmansey E, Trueman P, Gibbons G (2016) Estimated the clinical outcomes and cost differences between standard care with and without cadexomer iodine in the management of chronic venous ulcesrs using a Markov Model. Ostomy Wound Manage 62(6): 26-40.

4. Dalsing M (2015) The current state of deep venous valve repair. Vein Magazine.

5. Philips M, Dijkstra M, Khin N, Lane R (2013) Endovenous valve transfer for chronic deep venous insufficiency. Eur J Vasc Endovasc Surg 46(3): 360-365.

6. Pavcnik D, Yin Q, Uchida B, Park WK, Hoppe H, et al. (2007) Percutaneous autologous venous valve transplantation: Short-term feasibility study in an ovine model. J Vasc Surg 46(2): 338-345.

7. Pavcnik D, Kaufman J, Uchida B, Correa L, Hiraki T, et al. (2004) Secondgeneration percutaneous bioprosthetic valve: a short-term study I sheep. J Vasc Surg 40(6): 1223-1227.

8. Gomez Jorge J, Venbrux AC, Magee C (2000) Percutaneous deployment of a valved bovine jugular vein in the swine venous system: a potential treatment for venous insufficiency. J Vasc Interv Radiol 11(7): 931-936.

9. Dondossola E, Holzapfel BM, Alexander S, Filippini S, Hutmacher DW, et al. (2016) Examination of the foreign body response to biomaterials by nonlinear intravital microscopy. Nat Biomed Eng 1: 0007.

10. Asawa, Y, Sakamoto T, Komura M, Watanabe M, Nishizawa S, et al. (2012) Early stage foreign body reaction against biodegradable polymer scaffolds affects tissue regeneration during autologous transplantation of tissue-engineered cartilage in the canine model. Cell Transplant 21(7): 1431-1442.

11. Mogaldea A, Goecke T, Theodoridis K, Haverich A, Cebotari S, et al. (2017) Tissue engineering of vein valves based on decellularized natural matrices. Cell Tissues Organs 204(3-4): 199-209.

12. Weber B, Robert J, Ksiazek A, Wyss Y, Frese L, et al. (2014) Livingengineered valves for transcatheter venous valve repair. Tissue Eng Part C Methods 20(6): 451-463.
ISSN: 2574-1241

\section{DOI: 10.26717/BISTR.2018.12.002253}

Yolanda Bryce. Biomed J Sci \& Tech Res

This work is licensed under Creative

Commons Attribution 4.0 License

Submission Link: https://biomedres.us/submit-manuscript.php

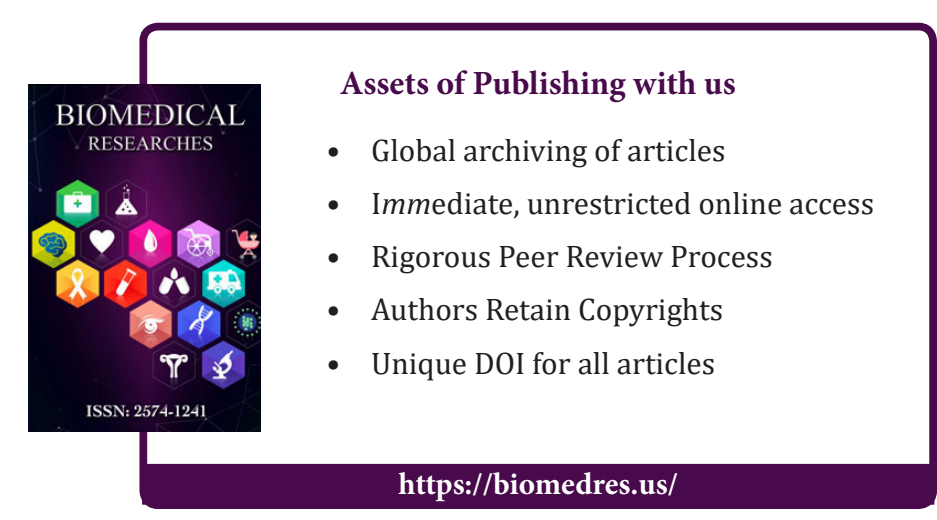

